\title{
STUDI PENGETAHUAN IBU NIFAS TENTANG TANDA BAHAYA SELAMA MASA NIFAS \\ (Di Desa Pomahan Janggan Kecamatan Turi Kabupaten Lamongan 2015)
}

\author{
Sumiyati* \\ Hetti Latifah** \\ *Dosen Program Studi D III Kebidanan Universitas Islam Lamongan \\ **Mahasiswa Program Studi D III Kebidanan Universitas Islam Lamongan
}

\begin{abstract}
ABSTRAK
Masa nifas berlangsung selama kira-kira 6-8 minggu, masa nifas masih beresiko mengalami perdarahan atau infeksi yang dapat menyebabkan kematian ibu. Pengetahuan ibu nifas tentang tanda bahaya selama masa nifas sangat minim sehingga paling sedikit 4 kali kunjungan pada masa nifas untuk menilai status ibu dan bayinya untuk melaksanakan screening yang komprehensif, mendeteksi masalah, mengobati atau merujuk bila terjadi komplikasi pada ibu dan bayi.

Desain yang digunakan dalam penelitian ini adalah deskriptif dengan menggunakan metode consecutive sampling. Sampling diambil dari jumlah populasi yaitu 15 ibu nifas dengan menggunakan alat ukur kuesioner.

Hasil penelitian didapatkan sebagian besar responden berpengetahuan kurang yaitu reponden dan sebagian kecil berpengetahuan baik yaitu responden tentang tanda bahaya selama masa nifas.

Baik kurangnya pengetahuan ibu nifas di pengaruhi oleh beberapa faktor yaitu pendidikan, umur, pekerjaan, pengalaman, lingkungan, informasi, sosial ekonomi dan sosial budaya.

Dari penelitian diatas diharapkan ibu nifas lebih peka dalam mendeteksi tanda bahaya selama masa nifas. Selain itu bagi petugas kesehatan agar mengoptimalkan perannya sebagai konselor sehingga mencegah komplikasi selama masa nifas.
\end{abstract}

Kata kunci : Pengetahuan, ibu nifas, tanda bahaya

\section{PENDAHULUAN}

Masa nifas berlangsung selama kira-kira 6-8 minggu (Sarwono Prawirohardjo, 2005). Setelah melahirkan, ibu masih perlu mendapat perhatian. Masa nifas masih beresiko mengalami perdarahan atau infeksi yang dapat mengakibatkan kematian ibu. Untuk menjaga kesehatan ibu nifas dan bayi baru lahir baik persalinannya di tolong oleh tenaga kesehatan atau tidak harus mendapat post natal care (pelayanan nifas). Menurut program safe motherhood ( Depkes, 2002) cakupan pelayanan nifas berdasarkan indikator pelayanan neonatal/KN (kunjungan neonatal) dengan asumsi pada saat melakukan pemeriksaan neonatal juga melakukan pemeriksaan terhadap ibunya. Pelayanan kunjungan nifas juga tidak berarti ibu nifas yang mendatangi tenaga kesehatan atau fasilitas kesehatan namun di definisikan sebagai kontak ibu nifas dengan tenaga kesehatan baik di dalam gedung maupun di luar gedung fasilitas kesehatan (termasuk bidan di desa/polindes/poskesdes dan 
kunjungan rumah (Buku PWS KIA, Depkes, 2003) (Riskesdas 2010)

Memperhatikan angka

kematian ibu dan perinatal dapat diperkirakan bahwa sekitar $60 \%$ kematian ibu akibat kehamilan terjadi setelah persalinan dan 50\% kematian masa nifas terjadi dalam 24 jam pertama. (Prawirohardjo, 2002).

Berdasarkan penelitian di BPS Ny Nurbani, Amd. Keb selama bulan Mei sampai Juni 2015 terdapat sebanyak 15 orang ibu nifas yang ada di Polindes Pomahan Janggan Kecamatan Turi Kabupaten Lamongan dari bulan Januari-Maret 2015 dan dari 15 orang ibu nifas yang mengalami bahaya masa nifas 1 orang mengalami bendungan ASI, 1 orang mengalami bengkak pada seluruh tubuh, 1 orang mengalami sub involusi uteri yang di sebabkan tidak mau melakukan mobilisasi dini.

Berdasarkan uraian di atas di dapatkan 3 orang yang mempunyai masalah bahaya masa nifas. Data tersebut merupakan sebagian data dari ibu nifas dengan masalah bahaya masa nifas yang di ketahui atau terdeteksi oleh tenaga kesehatan. Tapi sebenarnya masih banyak ibu nifas yang mengalami masalah bahaya masa nifas, yang tidak di ketahui atau terdeteksi oleh tenaga kesehatan. Penyebab tidak di ketahuinya masalah bahaya masa nifas yaitu kurangnya pengetahuan ibu nifas. Dimana yang mempengaruhi pengetahuan dari ibu nifas yaitu faktor yang mempengaruhi pengetahuan (pendidikan, usia, pekerjaan, informasi, pengalaman, lingkungan, sosial ekonomi, sosial budaya) dan juga konseling dari tenaga kesehatan selama kehamilan dan setelah persalinan (Notoadmodjo, 2010).
Pada wanita atau ibu nifas penjelasan mengenai tanda-tanda bahaya masa nifas sangat penting dan perlu, oleh karena masih banyak ibu atau wanita yang sedang hamil atau pada masa nifas belum mengetahui tentang tanda-tanda bahaya masa nifas, baik yang diakibatkan masuknya kuman kedalam alat kandungan seperti eksogen (kuman datang dari luar), autogen (kuman masuk dari tempat lain dalam tubuh) dan endogen (dari jalan lahir sendiri)

(Rostam Muchtar, 1998)

Faktor dominan yang mempengaruhi adalah kurang terdeteksinya faktor-faktor komplikasi secara dini. Untuk itu diperlukannya peran serta masyarakat terutama ibu-ibu nifas untuk memiliki pengetahuan tentang tanda-tanda bahaya pada masa nifas sehingga ibu dapat mengetahui dan mengenal secara dini tanda-tanda bahaya masa nifas, apabila ada kelainan dan komplikasi dapat segera terdeteksi.

Asuhan pada masa nifas sangat diperlukan dalam periode ini karena masa nifas merupakan masa kritis untuk ibu dan bayinya. Paling sedikit 4 kali kunjungan pada masa nifas sehingga dapat menilai status ibu dan bayinya, untuk melaksanakan skreening yang komprehensif mendeteksi masalah, mengobati atau merujuk bila terjadi komplikasi pada ibu dan bayi, sehingga ibu-ibu nifas dapat mencegah komplikasi yang terjadi pada masa nifas (Prawirohardjo, 2002).

Apabila ibu nifas mengerti tentang tanda-tanda bahaya masa nifas, maka apabila terjadi masalahmasalah seperti infeksi nifas maka ibu akan mengerti dan segera 
memeriksakan diri ke petugas kesehatan, Sebaliknya jika ibu tidak mengerti tanda-tanda bahaya masa nifas maka ibu tidak akan tahu apakah ibu dalam bahaya atau tidak.

\section{PEMBAHASAN}

\section{Data Umum}

Karakteristik Responden

1) Umur

Tabel 1

Distribusi Responden berdasarkan umur di Desa Pomahan Janggan Kecamatan Turi Kabupaten Lamongan

\begin{tabular}{|c|c|c|c|}
\hline No. & Umur & $\mathrm{N}$ & $\%$ \\
\hline 1. & $\leq 20$ & 10 & $66,7 \%$ \\
2. & $21-35$ & 3 & $20 \%$ \\
3. & $>35$ & 2 & $13,3 \%$ \\
\hline \multicolumn{2}{|c|}{ Total } & 15 & $100 \%$ \\
\hline
\end{tabular}

Dari tabel 1 di atas diketahui sebagian besar responden berumur $\leq$ 20 tahun yaitu $(66,7 \%)$ responden dan sebagian kecil responden berumur > 35 tahun yaitu $(13,3 \%)$ responden

2) Pendidikan

Tabel 2 Distribusi responden berdasarkan pendidikan di Desa Pomahan Janggan Kecamatan Turi Kabupaten Lamongan

\begin{tabular}{|c|l|c|c|}
\hline No. & Pendidikan & $\mathrm{N}$ & $\%$ \\
\hline 1. & SD & 3 & 20 \\
2. & SMA & 12 & $\%$ \\
3. & PT & 0 & $80 \%$ \\
& & & $0 \%$ \\
\hline \multicolumn{2}{|c|}{ Total } & 15 & $\begin{array}{c}100 \\
\end{array}$ \\
\hline
\end{tabular}

Dari tabel 2 di atas diketahui sebagian besar responden berpendidikan Menengah yaitu 12 (80\%) responden dan sebagian kecil berpendidikan rendah 3 (20\%) responden.

3) Pengalaman

Tabel 3 Distribusi responden berdasarkan

Pengalaman di Desa Pomahan Janggan

Kecamatan Turi

Kabupaten Lamongan

\begin{tabular}{|c|cc|c|c|}
\hline No. & \multicolumn{2}{|c|}{ Pengalaman } & $\mathrm{N}$ & $\%$ \\
\hline 1. & 1 kali melahirkan & 11 & $73,3 \%$ \\
2. & 2 kali melahirkan & 1 & $06,7 \%$ \\
3. & $>2$ kali & 3 & $20 \%$ \\
& melahirkan & & \\
\hline \multicolumn{3}{|c|}{ Total } & 15 & $100 \%$ \\
\hline
\end{tabular}

Dari tabel 3 di atas diketahui sebagian besar responden melahirkan 1 kali/pertama yaitu $11(73,3 \%)$ responden dan sebagian kecil pernah melahirkan 2 kali yaitu $1(06,7 \%)$ responden.

\section{Data Khusus}

Pengetahuan Ibu nifas tentang tanda bahaya selama masa nifas

Tabel 5 Distribusi pengetahuan ibu nifas tentang tanda bahaya selama masa nifas di Desa Pomahan Janggan Kecamatan Turi Kabupaten Lamongan

\begin{tabular}{|c|l|c|c|}
\hline No. & Pengetahuan & N & $\%$ \\
\hline 1. & Baik & 3 & $20, \%$ \\
2. & Cukup & 4 & 26,7 \\
3. & Kurang & 8 & $\%$ \\
& & & $53,3 \%$ \\
\hline \multicolumn{2}{|c|}{ Total } & 15 & $100 \%$ \\
\hline
\end{tabular}

Dari tabel 5 di atas diketahui kebanyakan responden berpengetahuan kurang yaitu 8 ibu nifas $(53,3 \%)$ responden dan sebagian kecil berpengetahuan baik yaitu 3 ibu nifas (20\%) 


\section{Pembahasan}

Dari hasil pengumpulan data distribusi responden berdasarkan umur seperti pada tabel 1 di dapatkan sebagian besar responden berumur $\leq 20$ tahun, yaitu sebanyak $10 \mathrm{ibu}$ nifas $(66,7 \%)$

Menurut Elizabeth yang di kutip oleh Nur Salam (2003), usia adalah umur individu yang terhitung mulai saat di lahirkan sampai saat berulang tahun, semakin cukup umur, tingkat kematangan dan kekuatan seseorang akan lebih matang dalam berfikir dan bekerja.

Hal itu selaras dengan pernyataan dari Long yang di kutip oleh Nur Salam (2003), makin tua umur seseorang, makin konstruktif dalam menghadapi masalah yang di hadapi.

Semakin banyak umur atau semakin tua seseorang maka akan mempunyai kesempatan dan waktu yang lebih lama dalam mendapatkan informasi dan pengetahuan. Dengan demikian semakin tua umur responden maka tingkat pengetahuan ibu nifas tentang tanda-tanda bahaya masa nifas semakin baik.

Dari hasil pengumpulan data distribusi responden menurut pendidikan, seperti pada tabel 5.2 didapatkan bahwa sebagian besar responden tingkat pendidikannya menengah yaitu sebanyak $12 \mathrm{ibu}$ nifas $(80 \%)$

Menurut Kuncoroningrat yang dikutip oleh Nursalam (2003), bahwa makin tinggi pendidikan seseorang, maka makin mudah menerima informasi sehingga makin banyak pula pengetahuan yang dimiliki. Responden yang berpendidikan tinggi akan mudah menyerap informasi, sehingga ilmu pengetahuan yang dimiliki lebih tinggi namun sebaliknya orang tua yang berpendidikan rendah akan mengalami hambatan dalam penyerapan informasi sehingga ilmu yang dimiliki juga lebih rendah yang berdampak pada kehidupannya.

Hal tersebut juga disebabkan oleh faktor pengalaman. Dari tabel 5.3 hampir sebagian ibu nifas baru pertama kali melahirkan yaitu sebanyak 11 orang $(73,3 \%)$,

Menurut Notoadmodjo (2010) pengalaman merupakan suatu cara untuk memperoleh kebenaran pengetahuan. Pengalaman dapat menuntun seseorang untuk menarik kesimpulan dengan benar, sehingga dari pengalaman yang benar di perlukan berfikir yang logis dan kritis.

Hal ini membuktikan bahwa umur, pendidikan dan pengalaman sangat berpengaruh terhadap pengetahuan seseorang dimana semakin tua umur seseorang semakin banyak pengetahuan yang di miliki, semakin tinggi pendidikan semakin banyak pengetahuan yang di dapat dan juga semakin sering pengalaman ibu melahirkan semakin banyak pengetahuan yang di peroleh tentang tanda bahaya selama masa nifas.

\section{Keterbatasan}

Keterbatasan adalah kelemahan atau hambatan dalam penelitian. Dalam hal ini peneliti akan melakukan seminimal mungkin disebabkan karena hal sebagai berikut:

a. Pengumpulan data dengan kuesioner memiliki jawaban lebih banyak di pengaruhi sikap dan harapan-harapan pribadi yang bersifat obyektif. Teknik sampling non random hasil tidak bisa di generalisasi.

b. Instrumen yang digunakan yaitu kuesioner tertutup kelemahannya 
bersifat subjektif atau responden tidak mengerti tentang pertanyaan yang diberikan.

\section{Kesimpulan}

Setelah menganalisis data dan melihat hasil pembahasan maka peneliti dapat mengambil kesimpulan sebagai berikut :

Hampir seluruhnya ibu nifas di Desa Pomahan Janggan Kecamatan Turi Kabupaten Lamonganmempunyai pengetahuan kurang tentan tanda bahaya selama masa nifas.

\section{Saran}

Dari kesimpulan diatas, peneliti dapat memberikan saran sebagai berikut :

a. Bagi Responden. Untuk responden khususnya ibu nifas lebih aktif dalam menanyakan hal-hal yang berhubungan dengan kondisinya sehingga dapat mudah mendeteksi adanya kelainankelainan pada ibu.

b. Bagi Tenaga Kesehatan. Bagi tenaga kesehatan terutama bidan diharapkan senantiasa melakukan konseling agar meningkatkan pengetahuan ibu nifas terutama tentang tanda bahaya selama masa nifas.

c. Bagi Peneliti Selanjutnya. Hendaknya penelitian ini dapat dijadikan data awal penelitian, untuk dapat dikembangkan lebih luas dan mengambil sampel lebih banyak sehingga hasilnya lebih representatif.

\section{DAFTAR PUSTAKA}

Departemen Kesehatan RI. 2001.

Buku Pedoman Petugas

Fasilitas Pelayanan keluarga Berencana. Jakarta: Bina Kesehatan Masyarakat.
Glasier, Anna. 2005. Keluarga Berencana dan Kesehatan Reproduksi. Jakarta: EGC.

Hartanto, Hanafi. 2004. Keluarga Berencana dan kontrasepsi. Jakarta: Puspa Sinar Harapan.

Hidayat, Alimul Aziz, (2010). Metode Penelitian Kebidanan dan Teknik Analisis Data. Jakarta. Salemba Medika.

Kuntoro, Haji. 2007. Metode Statistik. Surabaya, Pustaka Melati.

Manuaba, IGB, (1998). Ilmu Kebidanan, Penyakit kandungan, dan KB. EGC. Jakarta

Mochtar, R. (1998). Sinopsis Obstetri, Obstetri Fisiologi, Obstetri Patologi, bagian 1. EGC, Jakarta.

Nursalam, (2008). Konsep dan Penerapan Metodologi Penelitian Ilmu Keperawatan. Salemba Medika. Jakarta.

Nursalam dan Siti Pariani (2001). Pendekatan Praktis dan Metodologi Riset Keperawatan. Sagung Seto. Jakarta.

Prawirihardjo, W, (1999). Ilmu Kebidanan, Jakarta. YBP-SP.

Prastowo, Andi. 2015. Memahami Metode-Metode Penelitian. Jogjakarta: Ar-Ruz Media.

Purnomo, W. (2002). Metodologi Penelitian, Hand out dan Bahan Kuliah.

Saifuddin, AB, dkk. (2003). Buku panduan Praktis Pelayanan Kontrasepsi, Jakarta. YBP-SP.

Soekidjo, Notoatmodjo. (2005), Metodologi Penelitian Kesehatan. Rineka Cipta. Jakarta.

Suharsimi, Arikunto (1998). Prosedur Penelitian Suatu Pendekatan Praktek. Jakarta. Rineka Cipta 